\title{
Increasing optimism abolishes pain-induced impairments in executive task performance
}

Citation for published version (APA):

Boselie, J. L. M., Vancleef, L. M. G., Smeets, T., \& Peters, M. L. (2014). Increasing optimism abolishes pain-induced impairments in executive task performance. Pain, 155(2), 334-340.

https://doi.org/10.1016/j.pain.2013.10.014

Document status and date:

Published: 01/02/2014

DOI:

10.1016/j.pain.2013.10.014

Document Version:

Publisher's PDF, also known as Version of record

Document license:

Taverne

Please check the document version of this publication:

- A submitted manuscript is the version of the article upon submission and before peer-review. There can be important differences between the submitted version and the official published version of record.

People interested in the research are advised to contact the author for the final version of the publication, or visit the DOI to the publisher's website.

- The final author version and the galley proof are versions of the publication after peer review.

- The final published version features the final layout of the paper including the volume, issue and page numbers.

Link to publication

\footnotetext{
General rights rights.

- You may freely distribute the URL identifying the publication in the public portal. please follow below link for the End User Agreement:

www.umlib.nl/taverne-license

Take down policy

If you believe that this document breaches copyright please contact us at:

repository@maastrichtuniversity.nl

providing details and we will investigate your claim.
}

Copyright and moral rights for the publications made accessible in the public portal are retained by the authors and/or other copyright owners and it is a condition of accessing publications that users recognise and abide by the legal requirements associated with these

- Users may download and print one copy of any publication from the public portal for the purpose of private study or research.

- You may not further distribute the material or use it for any profit-making activity or commercial gain

If the publication is distributed under the terms of Article $25 \mathrm{fa}$ of the Dutch Copyright Act, indicated by the "Taverne" license above, 


\title{
Increasing optimism abolishes pain-induced impairments in executive task performance
}

\author{
Jantine J.L.M. Boselie*, Linda M.G. Vancleef, Tom Smeets, Madelon L. Peters \\ Clinical Psychological Science, Maastricht University, Maastricht, The Netherlands
}

Sponsorships or competing interests that may be relevant to content are disclosed at the end of this article.

\section{A R T I C L E I N F O}

\section{Article history:}

Received 22 March 2013

Received in revised form 27 September 2013

Accepted 15 October 2013

\section{Keywords:}

Executive functioning

Intervention

Optimism

Pain

Self-regulation

\begin{abstract}
A B S T R A C T
Coping with the demands of pain diminishes self-regulatory capacity and causes self-regulatory fatigue, which then leads to deteriorated executive task performance. It has been suggested that optimism can counteract the depletion of self-regulatory capacity. This study employed a 2 (optimism/no optimism) $\times 2$ (pain/no pain) between-subjects design to explore whether (1) experimentally induced pain (cold pressor task) deteriorates subsequent executive task performance, and (2) whether an optimism induction can counteract this sustained deteriorating effect of pain on executive task performance. Results indicated that although pain led to significantly worse performance on the executive functioning task in the no optimism condition, this sustained deteriorating effect of pain on task performance was abolished in the optimism condition. This finding is imperative because it suggests that optimism may be an important factor to implement in current psychological treatment approaches to diminish the negative impact of chronic pain on the ability to function in daily life.
\end{abstract}

(c) 2013 International Association for the Study of Pain. Published by Elsevier B.V. All rights reserved.

\section{Introduction}

Pain interrupts, interferes, and deteriorates executive task performance because pain attracts an individual's attention $[10,20,21,37]$. Prior studies on the interruptive effect of pain have routinely adopted dual-task paradigms that present painful stimuli during executive tasks performance $[10,36,37]$. Although this approach is highly suitable for testing the effects of pain on attention, it does not allow for the examination of whether pain might have sustained deteriorating effects on task performance [55]. The experience of pain may fatigue self-regulation resources, leading to deterioration in executive task performance [54]. Self-regulation is the ability to control or alter thoughts, emotion, and behaviour $[5,11]$. Coping with the demands of pain requires self-regulation, but this capacity is limited $[21,54,55]$. Self-regulation ability, to some extent, depends on executive functioning capacity, the ability to actively monitor behaviour, thoughts, and memory [52]. Ironically, self-regulatory efforts reduce executive functioning ability $[9,27,30,54]$, causing a downward spiral to ensue in which selfregulatory demands cause self-regulatory fatigue, reducing executive functioning capacity, making it more difficult to meet

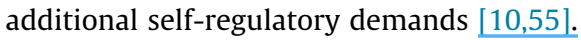

\footnotetext{
* Corresponding author. Address: Clinical Psychological Science, Maastricht University, P.O. Box 616, 6200 MD Maastricht, The Netherlands. Tel.: +31 043388 4325.

E-mail address: jantine.boselie@maastrichtuniversity.nl (J.J.L.M. Boselie).
}

People differ in their executive functioning and self-regulatory capacity [7]. One important individual difference variable in this respect may be optimism $[46,53,65]$. Optimism reflects an individual's tendency to expect that good things will happen in the future [44]. Optimism has a substantial impact on an individual's ability to cope with adversity, as optimists are more inclined to display approach coping strategies that are aimed at eliminating or managing stressors $[56,57]$. When confronted with pain, optimists are more likely to continue investing effort to obtain their goals $[1,13,19]$ and show better adaptation to pain $[2,8]$. These beneficial effects of optimism may be related to higher self-regulatory and executive functioning capacity, leading to higher goal perseverance and adaptation to the challenges of pain $[46,65]$.

This study examines whether optimism abolishes the deteriorating effect of pain on executive task performance. In the present study, the executive functioning task occurred after the pain induction to allow testing the hypothesis that pain has sustained deteriorating effects on executive functioning, thereby reflecting self-regulatory fatigue. In order to demonstrate that optimism causally influences the impact of pain on executive task performance, we employed an optimism induction manipulation. This manipulation is able to induce a temporary optimistic state and has previously been found to diminish self-regulatory fatigue [34] and pain sensitivity [25].

In summary, in order to test the hypotheses that (1) experimentally induced pain will deteriorate subsequent executive task 
performance and (2) an optimism induction counteracts this sustained deteriorating effect of pain on executive task performance, we set up an experiment in which participants completed an executive functioning task after being subjected to either painful cold water or comfortably warm water. Moreover, half of the participants received an optimism manipulation prior to the painful or nonpainful water task.

\section{Methods}

\subsection{Participants}

A total of 80 healthy undergraduates from Maastricht University participated in the study. Exclusion criteria were suffering from a chronic pain disorder or currently experiencing pain, cardiovascular disease, or Reynaud disease. Six participants were excluded from the analysis because they were nonnative Dutch speakers. Although the inclusion criteria only stated that a good comprehension of Dutch language was required, remembering unrelated 1-syllable Dutch words may add a level of complexity to the executive functioning task (see measures) for nonnative Dutch speakers. The remaining 74 participants ( 16 male) had a mean age of 21.9 years $(\mathrm{SD}=2.29)$. Participants were randomly assigned to 1 of the 4 conditions: (1) optimism and pain ( $\mathrm{n}=20,5$ male), (2) optimism and no pain ( $\mathrm{n}=18,4$ male), ( 3 ) no optimism and pain ( $\mathrm{n}=17,3$ male), and (4) no optimism and no pain ( $n=19,4$ male). Participants were informed during the recruitment that there was a possibility that they would be assigned to a pain condition. Participants received a gift voucher of 10 euro for their participation. The local ethical committee of the Faculty of Psychology and Neuroscience, Maastricht University, approved the study protocol.

\subsection{Manipulations}

\subsubsection{Optimism manipulation}

Optimism was induced by the Best Possible Self (BPS) manipulation, a positive future thinking technique based on work by King [31]. BPS has been proven effective in increasing positive affect and positive future expectancies $[25,40]$. Participants were instructed to carry out a writing and imagery exercise. Half of the participants were assigned to the BPS condition $(n=38)$, which required them to write about a life in the future where everything turned out for the best. The other half of the participants were assigned to the control condition $(n=36)$, which consisted of writing about a Typical Day (TD). The instructions were as follows [40,51]: BPS condition, "'Think about your best possible self means that you imagine yourself in the future, after everything has gone as well as it possibly could. You have worked hard and succeeded at accomplishing all the goals of your life. Think of this as the realization of your dreams, and that you have reached your full potential." TD condition, “'Think about your typical day' means that you take notice of ordinary details of your day that you usually don't think about. These might include particular classes or meetings you attend to, people you meet, things you do, typical thoughts you have during the day. Think of this as moving through your typical day, hour after hour."

Both manipulations had the same procedural format: participants were requested to think for 1 minute about what to write, then to write uninterrupted for 15 minutes, followed by 5 minutes of imaging the story they had just finished writing. Instructions were given both verbally and in writing.

\subsubsection{Pain manipulation}

In the pain condition ( $n=37$ ), the Cold Pressor Task (CPT) was used to induce a painful sensation. The water tank consisted of a
Plexiglas box (JULABO Labortechnik GmbH, Seelbach, Germany) filled with water that was kept constant at $2^{\circ} \mathrm{C}$ using an electrical immersion cooler (JULABO type FT200) and a circulation pump (JULABO type ED-19). The immersion duration was set at a maximum of 3 minutes [14]. Participants were explicitly informed that the procedure could be painful and that they could stop the task at any point without consequences. The instructions before immersion were as follows: "The aim of the task is to submerge your right hand in this cold water tank for as long as possible until you cannot take it anymore. When you cannot take it any longer, you are allowed to remove your hand from the water. Try, however, to hold on as long as possible." Participants were not aware of the preset time limit. If the 3-minute maximum was achieved, the experimenter signalled the participant to remove the hand from the water.

Participants in the no pain condition $(n=37)$ followed the same procedure, with the exception that the water temperature was a comfortable $34^{\circ} \mathrm{C}$ (warm water control task [WWCT]). Furthermore, to match immersion times of the CPT, participants were randomly requested to remove their hand from the water at 1,2 , or 3 minutes after immersion [47].

\subsection{Executive functioning}

\subsubsection{Operation-span task}

The operation-span task [60] is a working memory task that requires active maintenance of stored information while concurrently processing another source of information. In the operation-span task, participants have to remember and recall unrelated words in their order of presentation while simultaneously solving arithmetic problems. Processing the arithmetic problems interferes with recruitment of strategies, such as rehearsal or grouping, to maintain the stored information (ie, the words). The operation-span task relies on executive functioning capacity to overcome this interference and to help maintain and recall the presented words $[17,29]$. For this reason, the operation-span task is thought to reflect executive functioning $[23,28]$.

The task consists of 2 procedural aspects. First, participants read aloud a mathematical problem that consists of 2 arithmetic operations on 1 side of the equation and an offered solution on the other side of the equation. The first operation is a multiplication or division problem, the second operation contains an addition or subtraction problem (eg, is $(6 / 2)+5=8$ ?). The equation is presented centrally on a computer screen. After reading the mathematical problem aloud, the participant verbally states whether the offered solution is correct or incorrect, which the experimenter registers on an answer form. Second, behind each equation a 1-syllable word is presented, which has to be remembered for later serial recall (eg, is $(6 / 2)+5=8$ ? bread). The presented word is also read aloud by the participant. The presentation of the equation and word combination disappears from the screen when the participant presses the space key, introducing a 100 -ms blank interval before the next equation and word combination appears. The presentation of equation and word combinations continues until a question mark is presented on the screen. This signals the participant to start to write down the words in that trial, in order of presentation, on an answer sheet. The participants are informed that they should report as many words as were presented, and it is emphasized that the order of the words is important and that they are allowed to guess. There is no time constraint on this recall task.

In total, the operation-span task comprises 12 trials, preceded by 1 practice trial. One trial can consist of $2,3,4$, or 5 equation and word combinations, which are presented sequentially. Every possible trial length (eg, 2, 3, 4, or 5) is displayed 3 times. The presentation sequence of trials is randomized, which eliminates any strategy that is built on knowledge about the amount of words that 
need to be remembered [22]. Total duration of the operation-span task is approximately 12 minutes.

To ensure that the working memory load is high, an accuracy level of at least $85 \%$ for the processing component (eg, correct response to the mathematical problems) of the operation-span task is required. Data from participants who fail to achieve the preset accuracy rate of $85 \%$ are excluded from the analyses [16]. The operation-span task score is calculated with the Partial Credit Unit scoring (PCU) procedure [16,47]. The PCU represents the mean proportion of words that is recalled correctly. When 3 words are remembered correctly in a trial with 4 words, the score of this trial will be 0.75 [47]. The PCU score consists of the summed trial scores divided by the total number of trials (eg, 12). Scores range from 0 (no words recalled) to 1 (every word in every trial recalled correctly).

\subsection{Individual difference variables}

\subsubsection{Optimism}

The Life Orientation Test-Revised (LOT-R) [45] was used to assess the level of dispositional optimism. The LOT-R has 10 items that are rated on a 5-point Likert scale, ranging from 1 (strongly disagree) to 5 (strongly agree). There are 3 positively phrased items (eg, "I'm always optimistic about my future"), 3 negatively phrased items (eg, "I rarely count on good things happening to me"), and 4 filler items. The total score on the LOT-R is calculated from the positive and negative items and ranges from 10 to 30 , with higher scores reflecting higher levels of optimism. The LOT-R has been found to be a reliable and valid measurement instrument $[25,45]$.

\subsubsection{Pain catastrophizing}

The Pain Catastrophizing Scale (PCS) [58] is a 13-item scale that assesses catastrophic pain-related cognitive emotional processes. The participant has to recall former occurrences of pain and indicate to what degree they experienced the stated thoughts and feelings while experiencing pain (eg, "I keep thinking about how much it hurts"). Items are rated on a 5- point Likert scale, ranging from 0 (not at all) to 4 (all the time). The total PCS score can range from 0 to 52, with a higher score indicating greater pain catastrophizing [39]. Previous research had demonstrated that the PCS is a reliable and valid measurement instrument [39].

\subsection{Manipulation checks}

\subsubsection{Future expectancies}

The Future Expectancies Scale (FEX) [25] was administered to assess positive and negative future expectancies. The FEX consists of 20 statements regarding positive (eg, "people will admire you" or "you will be able to cope easily with pressure") and negative (eg, "things will not turn out as you had hoped" or "you will have health problems") future events. There are 10 positive and 10 negative items that cover 5 different domains (work, health, personal, social, and general). Participants rated the likelihood that they would experience the specific events on a 7-point Likert scale, ranging from 1 (not at all likely to occur) to 7 (extremely likely to occur). Higher scores reflect a higher estimated likelihood of positive (FEX-Pos) or negative (FEX-Neg) future events, with scores ranging from 10 to 70 . The internal consistency has previously been demonstrated to be satisfactory [25].

\subsubsection{Positive and negative mood}

The Positive and Negative Affect Schedule (PANAS) [61] is a 20item self-report measure of positive (PA, 10 items) and negative (NA, 10 items) affect. Participants indicated the degree to which a certain feeling (eg, anxious) was present at that moment on a 5-point Likert scale ranging from 1 (not at all) to 5 (extremely).
Subscale scores can range from 10 to 50, with higher scores on NA items reflecting higher levels of subjective distress and sadness. By contrast, higher scores on the PA scores correspond to higher levels of pleasurable feelings. The PANAS has been demonstrated to be valid and reliable [18].

\subsection{Pain outcome measures}

\subsubsection{Pain intensity}

Pain intensity after the CPT/WWCT was measured with a visual analogue scale (VAS, $100 \mathrm{~mm}$ ) with the labels "no pain at all" at one end and "extreme pain" on the other. Participants rated their pain intensity after withdrawing their hand from the CPT or WWCT on a VAS that was presented on the computer.

\subsubsection{Pain tolerance}

Pain tolerance is a behavioral measure of endurance and is defined as the immersion duration in seconds from the moment that the hand is placed in the water until the moment the hand is withdrawn from the water.

\subsection{Procedure}

Participants signed an informed consent form after receiving specific information about the procedure of their condition (ie, whether the water temperature was $2^{\circ} \mathrm{C}$ or $34^{\circ} \mathrm{C}$ ). They then filled out the questionnaires, including the FEX, PANAS, LOT-R, and PCS, via computer.

Next, participants received either the BPS manipulation (optimism; $n=37$ ) or the TD manipulation (no optimism; $n=35$ ). Then the FEX and the PANAS were administered a second time. Participants completed either the CPT $(n=37)$ until tolerance was reached or the WWCT $(n=37)$ with a preset immersion time of 1,2 , or 3 minutes. After withdrawal of the hand from the water, current pain intensity was rated on the VAS. Next, participants performed the operation-span task, after which they were thanked for their participation and received the remuneration. Participants were debriefed via e-mail when data collection for the study was completed.

\subsection{Data analyses}

Data were checked for normality and internal consistency of the FEX, LOT-R, PCS, and the PANAS questionnaires was calculated. A 2 -way analysis of variance (ANOVA) (optimism condition $\times$ pain) was conducted to check for baseline differences between conditions in age, PCS, optimism (LOT-R, FEX), and positive and negative affect (PANAS).

Next, manipulation checks were conducted. First, the effectiveness of the optimism manipulation on changes in self-reported positive and negative future expectancies and positive and negative affect was tested with a repeated-measures ANOVA with time (before vs after manipulation) as within-subjects factor and optimism condition (BPS vs TD) as between-subjects factor. This analysis was followed up within each condition with paired samples $t$ tests. Second, to check whether the pain manipulation was successful, an independent samples $t$ test (pain vs no pain) was conducted with pain intensity as dependent variable. In addition, because a previous study showed that the BPS manipulation decreased reported pain intensity during the cold pressor test [25], differences in pain intensity scores and pain tolerance between the BPS and TD conditions were examined with an independent samples $t$ test within the pain condition only.

The main analysis consisted of a 2 (optimism condition: BPS vs TD) $\times 2$ (pain condition: pain vs no pain) ANOVA to test the hypothesized interaction effect of pain and optimism on executive 
task performance. Participants not reaching pain tolerance within the maximum immersion period of 3 minutes were excluded from this analysis because these participants may not experience selfregulatory fatigue. Additionally, participants who failed to achieve the preset accuracy rate of $85 \%$ on the operation-span task were excluded from this analysis. Planned follow-up analyses were conducted to test the hypothesis that pain has a deteriorating effect on cognitive task performance in the TD condition, but not in the BPS condition.

All analyses were repeated with baseline positive and negative affect, dispositional optimism, and pain catastrophizing as covariates in separate analyses. Because these analyses yielded similar results, only the analyses without covariates will be reported. In addition, repeating the analyses while including the 6 nonnative Dutch speakers did not alter the pattern of results.

\section{Results}

\subsection{Baseline descriptives}

Age, the internal consistency, and the mean questionnaires scores of the participants $(\mathrm{N}=74)$ are presented in Table 1 by condition. Supporting successful randomization, 2-way ANOVAs did not reveal significant differences in age, positive and negative affect, dispositional optimism, or pain catastrophizing at baseline.

\subsection{Optimism (BPS) manipulation check}

The results of the repeated-measures ANOVAs revealed a significant time $\times$ optimism condition interaction for positive future expectancies $\left(F[1,72]=7.76, P=.007, \eta p^{2}=.10\right)$, negative future expectancies $\left(F[1,72]=7.29, P=.009, \eta p^{2}=.09\right)$, and positive affect $\left(F[1,72]=10.06, P=.002, \eta p^{2}=.12\right)$. For negative affect, only the main effect of time was significant $(F[1,72]=13.01, P=.001$, $\eta \mathrm{p}^{2}=.15$ ). Table 2 presents the results of the follow-up paired samples $t$ test. After receiving the BPS manipulation, participants reported significantly more positive future expectancies on the FEX-Pos and significantly less negative future expectancies on the FEX-Neg and less negative affect on the PANAS-NA. Furthermore, a trend toward significantly more positive affect on the PANAS-PA was found. Participants who received the TD manipulation reported a significant decrease in positive and negative affect on the PANAS. These results replicate previous findings that used this optimism manipulation $[25,40]$.

\subsection{Pain (CPT) manipulation check}

An independent samples $t$ test revealed a significant difference in pain intensity $(t[72]=20.43, P<.001, d=4.82,95 \%$ confidence interval [CI] of $d$ [3.91 to 5.73]). Participants in the pain condition reported significantly higher pain $(M=67.89, S D=19.27)$ than participants in the no pain condition $(M=1.61, S D=4.34)$.

\subsection{Pain intensity}

Within the pain condition, a $t$ test for independent groups was used to compare reported pain intensity of participants in the BPS and TD condition. Participants in the BPS condition $(M=68.80$, $\mathrm{SD}=19.70$ ) did not report lower pain intensity compared to participants in the TD condition $(M=66.82, S D=19.30)$ with $t(35)=0.31, P=.76, d=.10,95 \% \mathrm{CI}$ of $d(-0.57$ to 0.76$)$.

\subsection{Pain tolerance}

Similar to pain intensity, an independent samples $t$ test was conducted within the pain condition to compare pain tolerance of participants in the BPS and TD condition. Participants in the BPS condition $(M=72.40, S D=57.19)$ did not significantly differ in pain tolerance compared to participants in the TD condition $(\mathrm{M}=67.18, \mathrm{SD}=56.34)$, with $t(35)=0.28, P=.78, d=.09,95 \% \mathrm{CI}$ of $d(-0.57$ to 0.75$)$.

Although we aimed to match the average immersion time in the no pain condition to that in the pain condition, immersion times were significantly longer in the no pain condition $(M=115.14$, $\mathrm{SD}=55,46$ vs $\mathrm{M}=70.00, \mathrm{SD}=56.07, \quad t \quad[72]=3.48, \quad P=.001$, $d=.82,95 \% \mathrm{CI}$ of $d[0.33$ to 1.31$])$.

\subsection{Executive task performance}

Seven participants ( 5 male) in the pain condition were excluded from the analyses of executive task performance because they reached the preset tolerance time of 3 minutes ( 4 in the BPS condition, 3 in the TD condition) and therefore may not have experienced self-regulatory fatigue. Moreover, 1 participant (TD and no pain condition) was excluded because the preset accuracy level of $85 \%$ for the processing component of the operation-span task was not obtained (see Measures for details).

A 2 (optimism condition: BPS vs TD) $\times 2$ (pain condition: pain vs no pain) ANOVA with executive task performance (PCU score) as dependent variable revealed a significant optimism $\times$ pain interaction effect $\left(F[1,62]=5.10, P=.03, \eta p^{2}=.08\right)$. Planned follow-up analyses demonstrated that pain had a significant deteriorating effect on executive task performance in participants in the TD and pain condition ( $\mathrm{M}=0.67, \mathrm{SD}=0.12)$ compared to participants in the TD and no pain condition $(\mathrm{M}=0.79, \mathrm{SD}=0.11)$ with $t(30)=-2.90, P=.01, d=1.08,95 \% \mathrm{CI}$ of $d(0.32$ to 1.84$)$. Of crucial importance, and confirming our second hypothesis, the deteriorating effect of pain on executive task performance was not present when participants received the BPS manipulation. Participants in the BPS and pain condition $(\mathrm{M}=0.77, \mathrm{SD}=0.11)$ did not

Table 1

Age, internal consistency $(\alpha)$, mean $(\mathrm{M})$, and standard deviation (SD) on the questionnaires at baseline by condition.

\begin{tabular}{|c|c|c|c|c|c|c|c|}
\hline & \multicolumn{3}{|c|}{ Total $(\mathrm{N}=74)$} & \multicolumn{2}{|l|}{ Best Possible Self } & \multicolumn{2}{|l|}{ Typical Day } \\
\hline & $\alpha$ & $\mathrm{M}(\mathrm{SD})$ & Range & No pain $(n=18)$ & Pain $(n=20)$ & No pain $(n=19)$ & Pain $(\mathrm{n}=17)$ \\
\hline Age (SD) & & & & $22.61(2.62)$ & $22.15(2.37)$ & $21.42(2.34)$ & $21.29(1.65)$ \\
\hline Positive future expectancies (FEX-Pos) & .86 & $53.92(6.02)$ & $35-66$ & $55.33(5.72)$ & $53.15(6.75)$ & $54.17(4.84)$ & $52.06(6.92)$ \\
\hline Negative future expectancies (FEX-Neg) & .83 & $30.24(7.80)$ & $15-51$ & $30.22(7.93)$ & $29.70(7.19)$ & $31.17(8.45)$ & $30.18(8.43)$ \\
\hline Positive affectivity (PANAS-PA) & .86 & $31.09(6.71)$ & $11-46$ & $31.22(7.48)$ & $31.50(7.94)$ & $30.28(4.34)$ & $31.06(6.99)$ \\
\hline Negative affectivity (PANAS-NA) & .82 & $13.23(3.80)$ & $10-28$ & $11.89(2.72)$ & $13.25(3.70)$ & $13.72(3.74)$ & $14.12(4.87)$ \\
\hline Dispositional optimism (LOT-R) & .77 & $21.93(3.39)$ & $15-30$ & $22.44(3.96)$ & $21.95(3.14)$ & $22.22(2.98)$ & $21.00(3.66)$ \\
\hline Pain catastrophizing (PCS) & .86 & $14.28(6.77)$ & $5-34$ & $13.50(7.28)$ & $14.05(8.05)$ & $13.50(5.20)$ & $16.59(6.11)$ \\
\hline
\end{tabular}

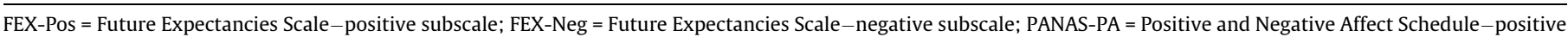

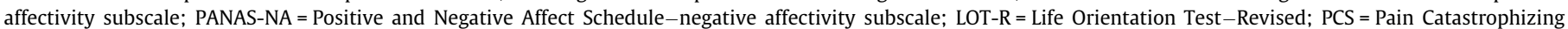
Scale. 
Table 2

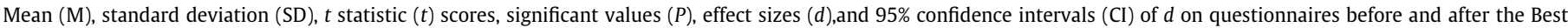
Possible Self or Typical Day manipulation.

\begin{tabular}{|c|c|c|c|c|c|c|c|c|c|c|c|c|}
\hline & \multicolumn{6}{|c|}{ Best Possible Self $(n=38)$} & \multicolumn{6}{|l|}{ Typical Day $(\mathrm{n}=36)$} \\
\hline & $\begin{array}{l}\text { Premanipulation M } \\
\text { (SD) }\end{array}$ & $\begin{array}{l}\text { Postmanipulation M } \\
\text { (SD) }\end{array}$ & $t$ & $P$ & $d$ & $95 \% \mathrm{CI}$ & $\begin{array}{l}\text { Premanipulation M } \\
\text { (SD) }\end{array}$ & $\begin{array}{l}\text { Postmanipulation M } \\
\text { (SD) }\end{array}$ & $t$ & $P$ & $d$ & $95 \% \mathrm{CI}$ \\
\hline FEX-Pos & $54.18(6.29)$ & $56.08(5.91)$ & 3.49 & .00 & .32 & -0.14 to 0.78 & $53.64(5.80)$ & $53.47(6.77)$ & -0.33 & .74 & .03 & -0.39 to 0.55 \\
\hline FEX-Neg & $29.95(7.45)$ & $26.21(7.04)$ & -5.35 & .00 & .52 & 0.06 to 0.98 & $30.56(8.25)$ & $29.44(9.01)$ & -1.65 & .11 & .13 & -0.34 to 0.60 \\
\hline PANAS-PA & $31.37(7.62)$ & $32.79(8.41)$ & 1.86 & .07 & .18 & -0.28 to 0.64 & $30.81(5.69)$ & $29.14(7.47)$ & -2.83 & .01 & .26 & -0.21 to 0.73 \\
\hline PANAS-NA & $12.61(3.30)$ & $11.82(2.78)$ & -2.90 & .01 & .26 & -0.20 to 0.72 & $13.89(4.21)$ & $12.36(2.65)$ & -2.57 & .02 & .44 & -0.03 to 0.91 \\
\hline
\end{tabular}

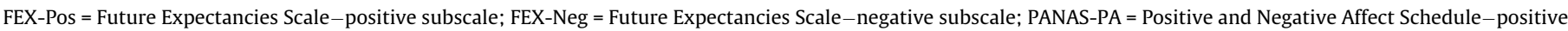
affectivity subscale; PANAS-NA = Positive and Negative Affect Schedule-negative affectivity subscale.

significantly differ with regard to their executive task performance when compared to participants in the BPS and no pain condition $(\mathrm{M}=0.76, \mathrm{SD}=0.10)$ with $t(32)=.11, P=.91, d=.10,95 \% \mathrm{CI}$ of $d$ $(-0.59$ to 0.79$)$. The results per condition are shown in Fig. 1.

We repeated the analyses including the 7 participants who did not reach pain tolerance within the 3-minute immersion period. Although the optimism $\times$ pain interaction did not reach significance $\left(F[1,69]=2.54, P=.12, \eta p^{2}=.04\right)$, the planned follow-up analyses within conditions showed a similar pattern as the main analyses: pain deteriorated executive task performance in participants in the TD condition (pain: $\mathrm{M}=0.69, \mathrm{SD}=0.12$; no pain: $\mathrm{M}=0.79, \mathrm{SD}=0.11 ; t[33]=-2.50, P=.02, d=.90,95 \% \mathrm{CI}$ of $d$ [0.18 to 1.62$]$ ) but not in the BPS condition (pain: $\mathrm{M}=0.75$, $\mathrm{SD}=0.11$; no pain condition: $\mathrm{M}=0.76, \mathrm{SD}=0.10 ; t[36]=-0.45$, $P=.66, d=.10,95 \% \mathrm{CI}$ of $d[-0.55$ to 0.75$])$.

\section{Discussion}

The results of the present study demonstrate that experimentally induced pain has a sustained deteriorating effect on subsequent executive task performance, and that inducing a temporary optimistic state can abolish this sustained deteriorating effect of pain on executive task performance.

Prior studies have demonstrated that pain interrupts attention and interferes with task performance predominantly by presenting a pain stimulus while simultaneously performing an executive functioning task [10,37]. In contrast, this study presented the executive functioning task after enduring a painful stimulus to examine whether pain has sustained deteriorating effects on subsequent task performance. As hypothesized, the results show that pain has sustained deteriorating effects, which may reflect self-regulatory fatigue. When an individual is confronted with a pain experience, self-regulatory resources are directed toward the pain in order to cope with this aversive experience. However, directing these resources toward the pain demand will render them unavailable for additional demands, causing self-regulation resources to be fatigued and task performance to decline [4-6].

Although we assume that the deteriorating effect of pain on executive functioning reflects self-regulatory fatigue, alternative explanations for the observed sustained deteriorating effect of pain are possible. Because the time period between the pain manipulation and executive working memory task was relatively short, the experience of residual pain could account for the deterioration in task performance. However, the cold pressor task has the advantage that pain rapidly decreases after stimulus termination [15]. Alternatively, acute stress may have caused the deterioration in executive task performance. Higher cortisol levels have been associated with larger decrements in executive task performance after a cold pressor task [47].

The primary purpose of this study was to examine whether optimism can protect against the sustained deteriorating effects of pain on executive task performance. A temporary optimistic state was induced with the BPS manipulation, which entails a writing and visualization exercise $[17,22]$. Although optimism has been defined as an enduring trait, optimism levels can change over time $[3,6]$. Previously it has been shown that daily imagery of BPS over a period of 2 weeks leads to sustained increases in optimism. This increase in optimism remained significant after controlling for positive affect and was not moderated by initial levels of dispositional optimism [35]. Using a single session of BPS writing and imagery, current results replicate prior findings $[25,40]$ in that the manipulation leads to significantly higher levels of positive affect and future expectancies and a decrease of negative future expectancies. Importantly, confirming our second hypothesis, the deteriorating effect of pain on executive task performance was not present in participants who received the optimism manipulation. This finding is indicative of the fact that optimism acts as a protective factor that may enhance self-regulatory capacity, abolishing the sustained deterioration effect of pain on executive task performance.

These findings might have clinical implications for patients with chronic pain. It has been proposed that chronic pain patients may suffer from chronic self-regulatory fatigue, causing problems in every domain that requires self-regulation [54]. Being able to accurately plan, organize, inhibit, and alter behaviour, emotions, and cognitions are essential abilities for individuals to function in daily life. Hence, increasing self-regulatory capacity will enable an individual with chronic pain to rely less on others, restoring their sense of independence and potentially reducing selfperceived burden among chronic pain patients [32]. When chronic pain patients do in fact experience chronic self-regulatory fatigue, it is essential to try and restore self-regulatory capacity, perhaps by interventions designed to enhance optimism and positive affect. Possible interventions are acceptance and commitment therapy [59,62], mindfulness-based cognitive therapy [24,63], positive psychotherapy [49], or implementing positive psychology exercises $[41,50,51,64]$ in current treatment approaches such as cognitivebehavioural therapy [38].

Previous studies showed that optimism increases the likelihood of goal achievement, as optimists tend to continue displaying effort to obtain their goals, even when confronted with pain $[1,13,19]$. One might argue that this higher tendency to pursue goal achievement may in fact be potentially harmful for chronic pain patients. Pain itself often cannot be remediated, thus pursuing the goal to abolish the pain experience may lead to disappointment and increased likelihood of experiencing goal conflict [56]. Goal conflict arises when pursuing one goal is at the cost of other goals [56] and can lead to decrements in overall well-being [12,43]. However, more optimistic individuals are able to cope with this conflict more efficiently and are able to disengage from a goal that is evaluated as unattainable $[13,33,42,48]$.

Some limitations should be taken into consideration when interpreting the current results. Although randomization was applied and participants did not differ on individual variables, such as dispositional optimism or pain catastrophizing, it cannot be 


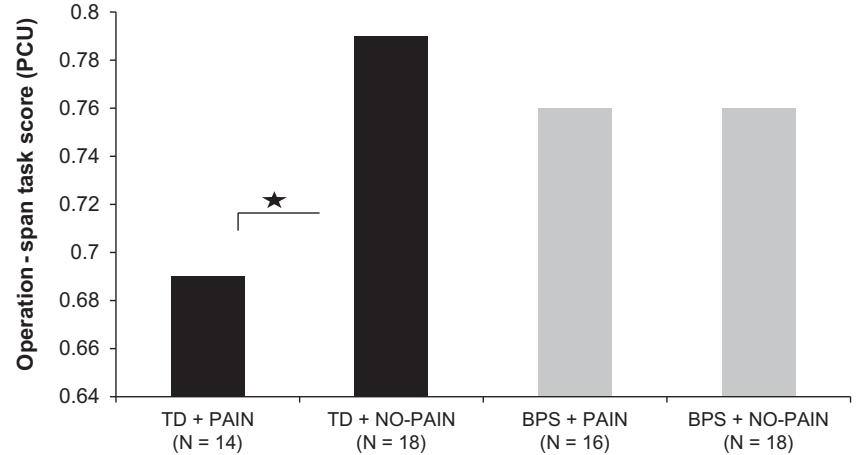

Fig. 1. Results on the operation-span task per condition. *A significance level of $P<.05$. $\mathrm{PCU}=$ Partial Credit Unit, $\mathrm{TD}=$ Typical Day, $\mathrm{BPS}=$ Best Possible Self.

excluded that participants may have differed on their executive functioning ability, which may have confounded the results. In order to eliminate this confounding, future research should include a preliminary measure of executive functioning. Additionally, recall duration of the operation-span task was not measured, which may have introduced a between-subjects factor that cannot be controlled for in the analyses. Furthermore, in addition to optimism, the BPS manipulation also increased positive affect. Therefore, it is not possible to disentangle the protective effects of these 2 interrelated constructs on pain-induced impairments in executive task performance.

It should be noted that the current study did not replicate the previous finding that the BPS manipulation reduced pain intensity reports after the pain manipulation [25]. Although both studies used the CPT as pain manipulation, these studies differed on 2 procedural aspects that may have caused the lack of replication of the previous finding. First, in the study by Hanssen et al. [25], a predetermined fixed immersion time of 1 minute had to be achieved, as opposed to reaching pain tolerance in the present study. Second, we only assessed pain intensity once after immersion, compared to several pain intensity assessments during and after immersion in the study by Hanssen et al. [25]. The very act of rating pain intensity can influence subsequent pain intensity ratings [26].

In conclusion, the present study shows that pain deteriorates performance on a subsequent executive functioning task. Additionally, a brief optimism induction was able to significantly abolish the sustained deteriorating effect of pain on executive functioning. We aim to extend these findings in chronic pain patients to examine whether optimism can be utilized to diminish the impact of pain on executive functioning when the pain itself often cannot be remediated.

\section{Conflict of interest statement}

There are no financial or other relationships that might lead to a conflict of interest.

\section{Acknowledgements}

This research was funded by grant 022.003 .038 from NWO, The Netherlands Organisation for Scientific Research, awarded to the Dutch-Flemish Research School of Experimental Psychopathology. The contribution of Madelon Peters is supported by a grant (Grant No. 110000007) from the Dutch Foundation of Scientific Research (Zon-MW). The contribution of Linda Vancleef is supported by the Netherlands Organization for Scientific Research (NWO: grant nr. 451-09-026).

\section{References}

[1] Affleck G, Tennen H, Zautra A, Urrows S, Abeles M, Karoly P. Women's pursuit of personal goals in daily life with fibromyalgia: a value-expectancy analysis. J Consult Clin Psychol 2001;69:587-96.

[2] Allison PJ, Guichard C, Gillain L. A prospective investigation of dispositional optimism as a predictor of health-related quality of life in head and neck cancer patients. Qual Life Res 2000;9:951-60.

[3] Apkarian AV, Sosa Y, Krauss BR, Thomas PS, Fredrickson BE, Levy RE, Harden RN, Chialvo DR. Chronic pain patients are impaired on an emotional decisionmaking task. PAIN ${ }^{\circledR} 2004 ; 108: 129-36$.

[4] Baumeister RF, Bratslavsky E, Muraven M, Tice DM. Ego depletion: is the active self a limited resource? J Pers Soc Psychol 1998;74:1252-65.

[5] Baumeister RF, Heatherton TF, Tice DM. Losing control: how and why people fail at self-regulation. San Diego, CA: Academic Press; 1994.

[6] Baumeister RFHTF. Self-regulation failure: an overview. Psychol Inq 1996;7:1.

[7] Berger A, Kofman O, Livneh U, Henik A. Multidisciplinary perspectives on attention and the development of self-regulation. Prog Neurobiol 2007;82:256-86.

[8] Brenes GA, Rapp SR, Rejeski WJ, Miller ME. Do optimism and pessimism predict physical functioning? J Behav Med 2002;25:219-31.

[9] Bridgett DJ, Oddi KB, Laake LM, Murdock KW, Bachmann MN. Integrating and differentiating aspects of self-regulation: effortful control, executive functioning, and links to negative affectivity. Emotion 2013:13:47-63.

[10] Buhle J, Wager TD. Performance-dependent inhibition of pain by an executive working memory task. PAIN ${ }^{\circledR}$ 2010;149:19-26.

[11] Carver CS, Scheier MF. On the self-regulation of behavior. On the selfregulation of behavior. New York, NY: Cambridge University Press; 1998.

[12] Carver CS, Scheier MF. Origins and functions of positive and negative affect: a control-process view. Psychol Rev 1990;97:19.

[13] Carver CS, Scheier MF, Segerstrom SC. Optimism. Clin Psychol Rev 2010;30:879-89.

[14] Chen AC, Dworkin SF, Haug J, Gehrig J. Human pain responsivity in a tonic pain model: psychological determinants. PAIN ${ }^{\circledR} 1989 ; 37: 143-60$.

[15] Conway A, Jarrold C, Kane M, Miyake A, Towse J. Variation in working memory. New York, NY: Oxford University Press; 2008.

[16] Conway ARA, Kane MJ, Bunting MF, Hambrick DZ, Wilhelm O, Engle RW. Working memory span tasks: a methodological review and user's guide. Psychon Bull Rev 2005;12:769-86.

[17] Conway ARA, Kane MJ, Engle RW. Working memory capacity and its relation to general intelligence. Trends Cogn Sci 2003;7:547-52.

[18] Crawford JR, Henry JD. The Positive and Negative Affect Schedule (PANAS): construct validity, measurement properties and normative data in a large nonclinical sample. Br J Clin Psychol 2004;43:245-65.

[19] Duke J, Leventhal H, Brownlee S, Leventhal EA. Giving up and replacing activities in response to illness. J Gerontol B Psychol Sci Soc Sci 2002;57B:P367-76.

[20] Eccleston C. Chronic pain and attention: a cognitive approach. Br J Clin Psychol 1994:33:535-47.

[21] Eccleston C, Crombez G. Pain demands attention: a cognitive-affective model of the interruptive function of pain. Psychol Bull 1999;125:356-66.

[22] Engle RW, Cantor J, Carullo JJ. Individual differences in working memory and comprehension: a test of four hypotheses. J Exp Psychol 1992;18:972-92.

[23] Engle RW, Kane MJ. Executive attention, working memory capacity, and a twofactor theory of cognitive control. In: Psychology of learning and motivation. New York, NY: Academic Press; 2003. p. 145-99.

[24] Grossman P, Niemann L, Schmidt S, Walach H. Mindfulness-based stress reduction and health benefits: a meta-analysis. J Psychosom Res 2004:57:35-43.

[25] Hanssen MM, Peters ML, Vlaeyen JW, Meevissen YM, Vancleef LM. Optimism lowers pain: evidence of the causal status and underlying mechanisms. PAIN ${ }^{\circledR}$ 2013;154:53-8.

[26] Hirsch MS, Liebert RM. The physical and psychological experience of pain: the effects of labeling and cold press or temperature on three pain measures in college women. PAIN ${ }^{\circledR} 1998 ; 77: 41-8$.

[27] Hofmann W, Schmeichel BJ, Baddeley AD. Executive functions and selfregulation. Trends Cogn Sci 2012;16:174-80.

[28] Kane M, Engle R. The role of prefrontal cortex in working-memory capacity, executive attention, and general fluid intelligence: an individual-differences perspective. Psychon Bull Rev 2002;9:637-71.

[29] Kane MJ, Conway AR, Hambrick DZ, Engle RW. Variation in working memory capacity as variation in executive attention and control. In: Conway AR, Jarrold C, Kane MJ, Miyake A, Towse JN, editors. Variation in working memory. New York: Oxford University Press; 2007. p. 21-48.

[30] Kaplan S, Berman MG. Directed attention as a common resource for executive functioning and self-regulation. Perspect Psychol Sci 2010;5:43-57.

[31] King LA. The health benefits of writing about life goals. Pers Soc Psychol Bull 2001;27:798-807.

[32] Kowal J, Wilson KG, McWilliams LA, Péloquin K, Duong D. Self-perceived burden in chronic pain: relevance, prevalence, and predictors. PAIN ${ }^{\circledR}$ 2012;153:1735-41.

[33] MacLeod AK. Affect, emotional disorder, and future-directed thinking. Cogn Emotion 1996;10:69-86.

[34] Meevissen YMC, Peters ML, Alberts HJEM. P02.48. Overcoming ego depletion: the effects of an optimism manipulation on repeated acts of selfcontrol. BMC Complem Altern Med 2012;12(Suppl 1):P104. 
[35] Meevissen YMC, Peters ML, Alberts HJEM. Become more optimistic by imagining a best possible self: effects of a two week intervention. J Behav Ther Exp Psychiatry 2011;42:371-8.

[36] Moore DJ, Keogh E, Eccleston C. The effect of threat on attentional interruption by pain. PAIN ${ }^{\circledR} 2013 ; 154: 82-8$.

[37] Moore DJ, Keogh E, Eccleston C. The interruptive effect of pain on attention. QJ Exp Psychol 2012;65:565-86.

[38] Morley S, Eccleston C, Williams A. Systematic review and meta-analysis of randomized controlled trials of cognitive behaviour therapy and behaviour therapy for chronic pain in adults, excluding headache. PAIN ${ }^{\circledR} 1999 ; 80$ : $1-13$.

[39] Osman A, Barrios FX, Gutierrez PM, Kopper BA, Merrifield T, Grittmann L. The Pain Catastrophizing Scale: further psychometric evaluation with adult samples. J Behav Med 2000;23:351-65.

[40] Peters ML, Flink IK, Boersma K, Linton SJ. Manipulating optimism: can imagining a best possible self be used to increase positive future expectancies? J Posit Psychol 2010;5:204-11.

[41] Rashid T, Ostermann RF. Strength-based assessment in clinical practice. J Clin Psychol 2009;65:488-98.

[42] Rasmussen HN, Wrosch C, Scheier MF, Carver CS. Self-regulation processes and health: the importance of optimism and goal adjustment. J Pers 2006;74:1721-47.

[43] Riediger M, Freund AM. Interference and facilitation among personal goals: differential associations with subjective well-being and persistent goal pursuit. Pers Soc Psychol Bull 2004;30:1511-23.

[44] Scheier MF, Carver CS. Optimism, coping, and health: assessment and implications of generalized outcome expectancies. Health Psychol $1985 ; 4: 219-47$.

[45] Scheier MF, Carver CS, Bridges MW. Distinguishing optimism from neuroticism (and trait anxiety, self-mastery, and self-esteem): a reevaluation of the Life Orientation Test. J Pers Soc Psychol 1994;67:1063-78.

[46] Schmitz U, Saile H, Nilges P. Coping with chronic pain: flexible goal adjustment as an interactive buffer against pain-related distress. PAIN ${ }^{\circledR}$ 1996;67:41-51.

[47] Schoofs D, Wolf OT, Smeets T. Cold pressor stress impairs performance on working memory tasks requiring executive functions in healthy young men. Behav Neurosci 2009;123:1066-75.

[48] Segerstrom SC, Nes LS. When goals conflict but people prosper: the case of dispositional optimism. J Res Pers 2006;40:675-93.

[49] Seligman ME, Rashid T, Parks AC. Positive psychotherapy. Am Psychol 2006;61:774.

[50] Seligman ME, Steen TA, Park N, Peterson C. Positive psychology progress: empirical validation of interventions. Am Psychol 2005;60:410.
[51] Sheldon KM, Lyubomirsky S. How to increase and sustain positive emotion: the effects of expressing gratitude and visualizing best possible selves. J Posit Psychol 2006; 1:73-82.

[52] Smith EE, Jonides J. Storage and executive processes in the frontal lobes. Science 1999;283:1657-61.

[53] Solberg Nes L, Carlson CR, Crofford LJ, de Leeuw R, Segerstrom SC. Individual differences and self-regulatory fatigue: optimism, conscientiousness, and selfconsciousness. Pers Indiv Diff 2011;50:475-80.

[54] Solberg Nes L, Carlson CR, Crofford LJ, de Leeuw R, Segerstrom SC. Selfregulatory deficits in fibromyalgia and temporomandibular disorders. PAIN 2010;151:37-44.

[55] Solberg Nes L, Roach AR, Segerstrom SC. Executive functions, self-regulation, and chronic pain: a review. Ann Behav Med 2009;37:173-83.

[56] Solberg Nes L, Segerstrom SC. Dispositional optimism and coping: a metaanalytic review. Pers Soc Psychol Rev 2006;10:235-51.

[57] Solberg Nes L, Segerstrom SC, Sephton SE. Engagement and arousal: optimism's effects during a brief stressor. Pers Soc Psychol Bull 2005;31:111-20.

[58] Sullivan MJL, Bishop SR, Pivik J. The Pain Catastrophizing Scale: development and validation. Psychol Assess 1995;7:524-32.

[59] Thorsell J, Finnes A, Dahl J, Lundgren T, Gybrant M, Gordh T, Buhrman M. A comparative study of 2 manual-based self-help interventions, acceptance and commitment therapy and applied relaxation, for persons with chronic pain. Clin J Pain 2011;27:716-23.

[60] Turner ML, Engle RW. Is working memory capacity task dependent? J Mem Lang 1989;28:127-54.

[61] Watson D, Clark LA, Tellegen A. Development and validation of brief measures of positive and negative affect: the PANAS scales. J Pers Soc Psychol 1988; $54: 1063-70$

[62] Wetherell JL, Afari N, Rutledge T, Sorrell JT, Stoddard JA, Petkus AJ, Solomon BC Lehman DH, Liu L, Lang AJ, Hampton Atkinson J. A randomized, controlled trial of acceptance and commitment therapy and cognitive-behavioral therapy for chronic pain. PAIN ${ }^{\circledR} 2011 ; 152: 2098-107$.

[63] Wong SY-S, Chan FW-K, Wong RL-P, Chu M-C, Lam Y-YK, Mercer SW, Ma SH Comparing the effectiveness of mindfulness-based stress reduction and multidisciplinary intervention programs for chronic pain: a randomized comparative trial. Clin J Pain 2011:27:724-34.

[64] Worthington E, Kurusu TA, Collins W, Berry JW, Ripley JS, Baier SN. Forgiving usually takes time: a lesson learned by studying interventions to promote forgiveness. J Psychol Theol 2000;28:3-20.

[65] Wrosch C, Scheier MF. Personality and quality of life: the importance of optimism and goal adjustment. Qual Life Res 2003;12:59-72. 